\title{
Improvement of tactile perception and enhancement of cortical excitability through intermittent theta burst rTMS over human primary somatosensory cortex
}

\author{
Patrick Ragert $\cdot$ Stephanie Franzkowiak • \\ Peter Schwenkreis · Martin Tegenthoff · \\ Hubert R. Dinse
}

Published online: 12 October 2007

(C) Springer-Verlag 2007

Erratum to: Exp Brain Res (2007)

DOI 10.1007/s00221-007-1073-2

The original version of this article unfortunately contained a mistake. The authors overlooked an erroneous reference to Fig. 5, which should have been removed. The fifth sentence in the third paragraph in the Discussion section
"Local specificity of iTBS-induced behavioral effects" should read as follows:

"Subjects did show some improvements, which, however, were not significant."

Moreover, the "present address" for the first author should read "National Institutes of Health" (not "Institute").

The online version of the original article can be found under doi: 10.1007/s00221-007-1073-2.

P. Ragert · S. Franzkowiak · H. R. Dinse

Institute for Neuroinformatics, Theoretical Biology,

Ruhr-University, 44780 Bochum, Germany

P. Ragert · P. Schwenkreis · M. Tegenthoff $(\varangle)$

Department of Neurology, BG-Kliniken Bergmannsheil,

Ruhr-University, 44789 Bochum, Germany

e-mail: martin.tegenthoff@rub.de

Present Address:

P. Ragert

Human Cortical Physiology Section,

National Institute of Neurological Disorders and Stroke,

National Institutes of Health, Bethesda, MD, USA 